\title{
Guideline for Developing High-density Recording Media Based on Magnetic Cluster Analysis
}

\author{
M. Hashimoto, H. Nakagawa, N. Ito, T. Ichihara, and K. Nakamoto \\ Central Research Laboratory, Hitachi Ltd., 2880 Kouzu, Odawara, Kanagawa 256-8510, Japan
}

\begin{abstract}
We examined the relationship between media cluster size distribution and signal quality to obtain a guideline for developing high-density recording media. Both spin-stand measurements and micromagnetics simulations were used. The cluster size distribution and SNR of various recording media were evaluated, and the relationship between the two was analyzed using multiple regression analysis. The results demonstrate that the media SNR could be quantitatively estimated from the cluster size distribution (both average sizes and size deviations). Although reducing either the average size or the size deviation was effective in terms of improving the SNR, the impact of the average was much larger. On the other hand, we also found that the effect of size deviation increased for the smaller average-sized media. We concluded that providing the guidelines for each individual developing medium is a key step and that the proposed analysis method is therefore effective.
\end{abstract}

Key words: Magnetic cluster size distribution, read-write performance, spin-stand measurement, capped perpendicular media

\section{磁気クラスタ解析に基づく記録媒体の高密度化指針}

橋本光弘・中川宏之・伊藤直人・市原貴幸・中本一広

日立製作所中央研究所，神奈川県小田原市国府津 2880 番地（テ256-8510）

1. はじめに

磁気記録によるストレージシステムの更なる高密度化には記録 再生特性の向上が必要である。そのためのアプローチには 2 種類 ある. 1 目はへッド・記録媒体などのコンポーネントデバイスに おける高密度化制限要因を改良することである. 2 つ目は，ヘッ ド・媒体の組み合わせ方や記録再生条件などの記録再生インテグ レーションの最適化である．磁気記録は摺り合わせ技術であるた め，課題を改善したデバイスを用いてもその組み合わせ等によっ てはかえって信号品質などの記録再生特性が劣化する場合がある。 従って，各デバイスの課題と記録再生特性の理解に基づいた開発 が重要である.

現状の垂直磁気記録においては記録媒体の磁気クラスタ形成に 起因した転移性ノイズやトラックエッジノイズが信号品質の支配 要因である ${ }^{1)-3)}$. 記録媒体の高密度化指針を得るには磁気クラスタ サイズ分布（平均サイズ・サイズ分散）と記録再生特性の関係を 定量的に明らかにする事が重要である，その為には，様々な記録 媒体について磁気クラスタサイズと記録再生特性の両者を評価す

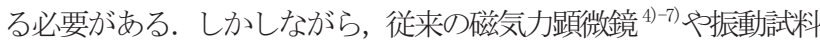
型磁力計 ${ }^{8)}$ を用いたクラスタサイズの評価では測定時間などの制 約により十分な数の媒体評価が困難であり，その関係は実験的に 十分に検討されているとは言えない.

我々は記録再生特性の評価装置であるスピンスタンドを用いた クラスタサイズ分布の簡便な評価手法を提案し9), 同手法を用いた 解析が記録再生特性の理解に有効であることを報告している ${ }^{10)}$.

本研究では，実験とシミュレーションにより磁気クラスタサイ ズ分布と記録再生特性の関係を整理し，媒体の高密度化指針につ いて検討したので報告する

\section{2. 実験およびシミュレーション条件}

実験では日立ハイテクノロジーズ社製スピンスタンド RH4160E を用い，チャンバー内の温度は 25 度に保って行った。 Table 1 に評価条件を示す。記録再生時は TFC(Thermal Flying-height Control)によりヘッド浮上量を制御した．線速度は $11.88 \mathrm{~m} / \mathrm{s}$ とした. 測定に用いた媒体はキャップ型垂直磁気記録媒 体 ${ }^{8)}$ であり, グラニュラ層の膜厚は 11.5 から $13 \mathrm{~nm}$, キャップ層 の膜㫗は 1 から $4.5 \mathrm{~nm}$ の範囲で変化させた．また，透過型電子顕 微鏡で観察された粒径はおよそ $10 \mathrm{~nm}$ であった。連続膜であるキ ヤップ層の膜厚を変えることで粒間交換結合力を制御できるため, 磁気クラスタ解析に適していると言える。記録へッドは WAS (Wrap Around Shield) 型の垂直記録ヘッド11)であり，再生ヘッドはシー ルドギャップ長が $33 \mathrm{~nm}$ の TMRヘッドを用いた．Lin らが提案する 微分法 ${ }^{12)}$ により算出した磁気的記録幅はおよ之 $120 \mathrm{~nm}$ であり，磁 気的再生幅は70 nm であった。媒体の AC 消去は記録へッドを用い て高周波磁界によりバンドイレーズを行った．その際，記録電流 を $35 \mathrm{~mA}$ ，ピッチを $20 \mathrm{~nm}$ ，周波数を $2400 \mathrm{kFCI}$ とし，再生トラッ クの周囲 $600 \mathrm{~nm}$ の幅で消去した.

シミュレーションでは，各パラメータは実験条件に合わせた。 記録計算は Landau-Lifshitz-Gilbert 方程式によるマイクロマグ ネティクスシミュレーションを行った. 記録ヘッドの磁界分布は 有限要素法により算出し，媒体モデルは粒径分布と異方性分散を 考慮したモデルを用いた。磁気クラスタサイズの解析は実験と同 様に記録へッドでACバンドイレーズした磁化分布を用いた。記録 計算の一例として，940kFCI の記録パターン(ビット長 $27 \mathrm{~nm}$ ), 及び AC バンドイレーズの磁化分布を Fig. 1 に示す. 再生計算は 再生へッドと媒体の構造をパラメータに算出した再生感度関数と 磁化分布の畳み込みにより行った。 
Table 1 RW evaluation conditions

\begin{tabular}{ll}
\hline Spin-stand & RH4160E \\
\hline Write current (mA) & 35 \\
\hline Read bias (mV) & 135 \\
\hline Radius (mm) & 21.0 \\
\hline Skew (deg.) & 0 \\
\hline Rot speed (rpm) & 5400 \\
\hline $\begin{array}{l}\text { Flying height of read } \\
\text { (nm) }\end{array}$ & $2 \mathrm{~nm}$ \\
\hline $\begin{array}{l}\text { Flying height of write } \\
(\mathrm{nm})\end{array}$ & $3 \mathrm{~nm}$ \\
\hline
\end{tabular}

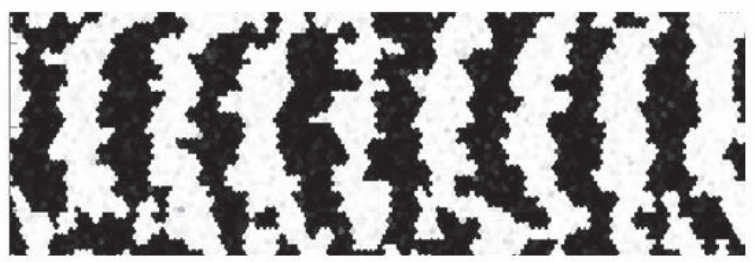

(a) Recorded bit pattern $(940 \mathrm{kFCl})$

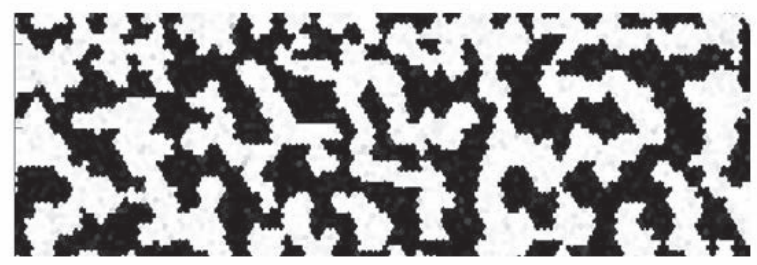

(b) AC band erased state

Fig. 1 Simulated magnetization distributions.

\section{3. 実験と計算の比較}

本研究では磁気クラスタサイズと信号品質の関係は実験と計算 を併用して検討した。本節ではそれらの一貫性について述べる。 実験，及び計算における SN 比の線記録密度依存性を Fig. 2 に示 す.ここで, SN 比は各線記録密度における信号振幅(zero-to-peak 值)とノイズの実効值電圧(0 440 MHz までの積分ノイズ)より算 出した. 両者の SN 比は線記録密度に依らず一致している. Fig. 3 には AC イレーズ状態の自己相関関数を示す. 実験においては $\mathrm{AC}$ イレーズスペクトラムからアンロードノイズスペクトラムと再生 感度関数の影響を除去した後, 逆フーリエ变換して算出した ${ }^{9)}$. シ ミュレーションでは磁化分布を直接自己相関演算を行った. 図中 には自己相関関数より算出した平均クラスタサイズ，及びクラス タサイズ分散も併せて示した．両者は一致しており，クラスタサ イズ分布と記録再生特性の関係は一貫している.

\section{4. 磁気クラスタサイズ分布と信号品質}

実験における磁気クラスタサイズの平均值と分散(平均值で規格

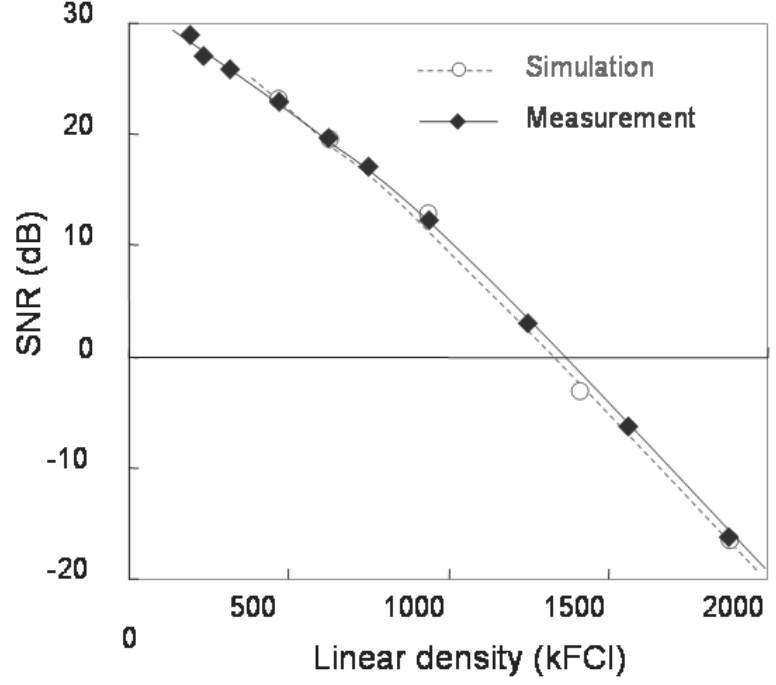

Fig. 2 SNR as a function of linear density.

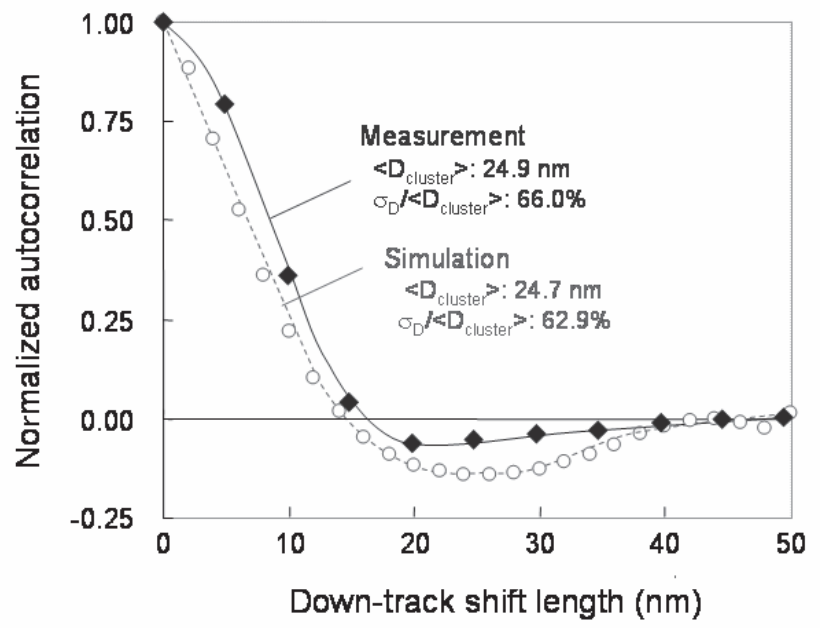

Fig. 3 Normalized autocorrelation functions of ac erased state.

化した標淮偏差)の相関を Fig. 4 に示す．両者はトレードオフの関 係にある. これは粒間交換結合力が強くなるに従ってより多くの 粒子が磁気クラスタを形成して平均サイズが増大寸る一方, その 平均化の効果により分散が低減すると理解できる，そこで，トレ ードオフの関係にある平均サイズとサイズ分散のうち，どちらが $\mathrm{SN}$ 比の向上に効果的であるか検討した。

磁気クラスタサイズ分布と SN 比の関係を定量化するため，重 回帰分析を行った. 回州分析ではデータが少ない領域における精 度が劣化するため, 実験結果とシミュレーション結果を併用した. なお，ライタビリティが十分でない媒体に関しては未飽和記録に 起因したノイズの影響が現れるため, $\mathrm{O} / \mathrm{W}$ が-40 dB 未満の十分に 飽和記録ができている媒体のみを解析に用いた。解析において, $\mathrm{SN}$ 比は平均サイズ $<D_{\text {cluster }}>$ とサイズ分散 $\sigma_{D} /<D_{\text {cluster }}>$ により表現 可能であり(1)式のように表せると仮定した.

$$
S N R=\alpha\left(<D_{\text {cluster }}>/ b\right)^{n 1}+\beta\left(\sigma_{D} /<D_{\text {cluster }}>\right)^{n 2}
$$




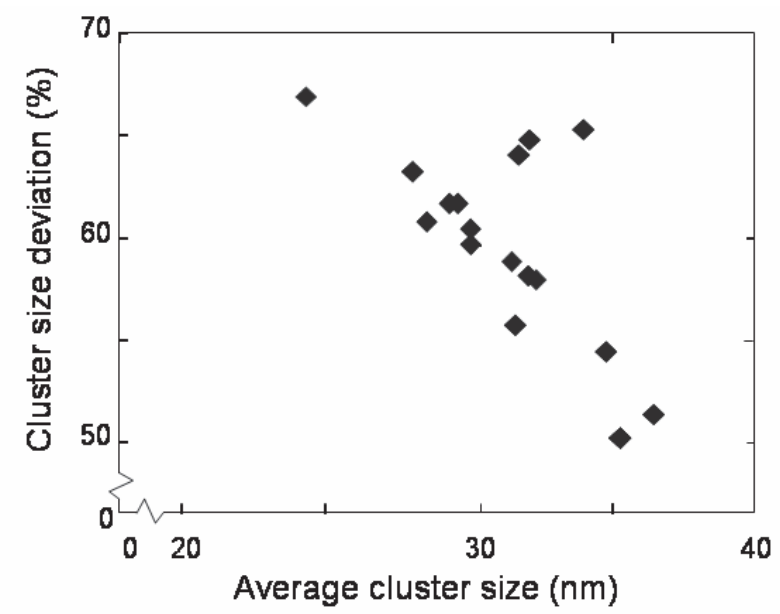

Fig. 4 Correlation between average cluster size and cluster size deviation.

Table 2 Coefficients obtained by regression analysis.

\begin{tabular}{cc}
\hline$\alpha$ & -2.65 \\
\hline$\beta$ & 15.1 \\
\hline $\mathrm{n} 1$ & 2.0 \\
\hline $\mathrm{n} 2$ & -0.1 \\
\hline
\end{tabular}

ここで， $b$ は記録ビット長， $\alpha, \beta, \mathrm{n} 1, \mathrm{n} 2$ は係数である．第一項は 平均サイズが SN 比に与える影響である. 平均サイズのみを減少 させた場合，転移幅の狭小化による分解能の向上や転移やトラッ クエッジの摇らぎ量の抑制によるノイズの低減により SN 比は向 上寸ると考えられる. 第二項は分散の SN 比への影響である. 均 質性が向上することで分解能やノイズは改善すると考えられる. パラメータとしてはサイズ分散の絶対值ではなく平均サイズで規 格化した值を用いた. Valcu らは信号品質の指標としてスイッチン グ磁界分散の絶対值よりも規格化した值を評価する方が重要であ ることを解析的に示している 13)。 サイズ分散とスイッチング磁界 分散は物理的に同一のものではないが, 両者には相関があり9)定性 的にValcu らの式と一致する. (1)式の 4 つ係数は同式に $<D_{\text {cluster }}>$ と $\sigma_{D} /<D_{\text {cluster }}>$ を代入して得られた $\mathrm{SN}$ 比の予測值が記録再生評価 により得られた結果と最もよく合致する様，最小二乗法により決 定した. 得られた係数を Table 2 に示寸. Fig. 5 に回帰分析結果を 用いて算出した SN 比の予測值と記録再生結果の相関を示寸。予 測值と実測值の誤差は標準偏差にして $0.3 \mathrm{~dB}$ と小さく, 媒体の違 いによる SN 比の優劣はクラスタサイズ分布によって説明できる.

続いて，この結果を利用して磁気クラスタサイズ分布と SN 比 の関係を整理した. SN 比の平均サイズ依存性及びサイズ分散依存 性をそれぞれ Fig. 6, 7 に示す. 各グラフにはサイズ分散, 及び平 均サイズの等高線も併せてプロットした. 等高線は(1)式に Table 2 の係数を代入して得られた関係式に平均サイズとサイズ分散を代 入して算出した. 通常, 平均サイズとサイズ分散は媒体によって 同時に変化するが等高線に沿ってデータを見ることでそれぞれの $\mathrm{SN}$ 比への影響を分離できる. 同図の等高線より平均サイズ，サイ ズ分散の低減はいずれも SN 比の向上に効果があることが確認で きる. しかしながら, 平均サイズの方が依存性の傾きが急峻であ

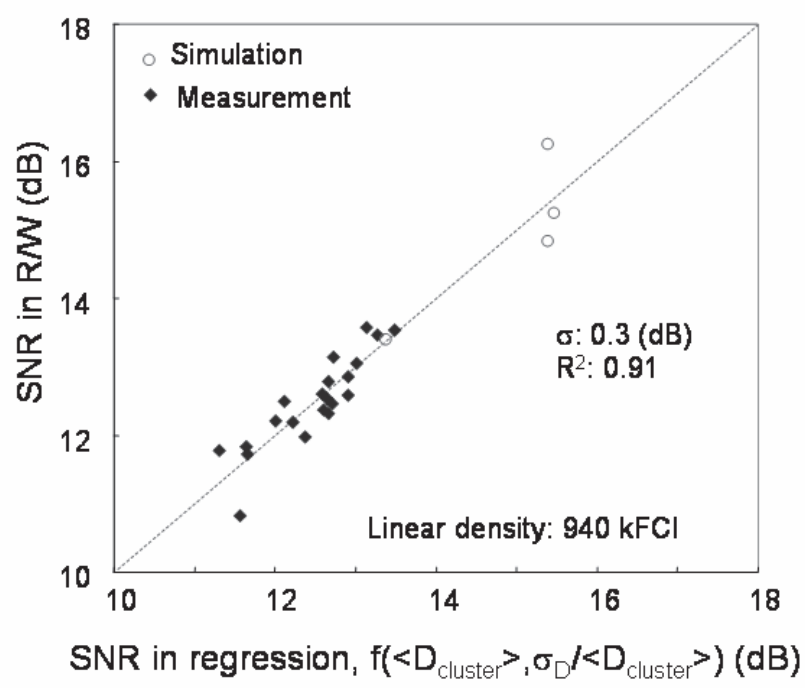

Fig. 5 Correlation between SNR by read-write evaluation and by regression.

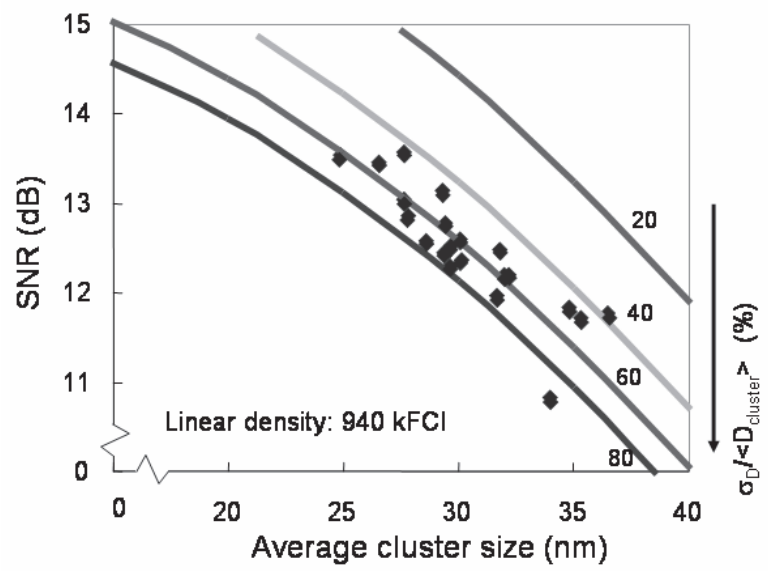

Fig. 6 SNR versus average cluster size. The contour lines of cluster size deviation are also plotted.

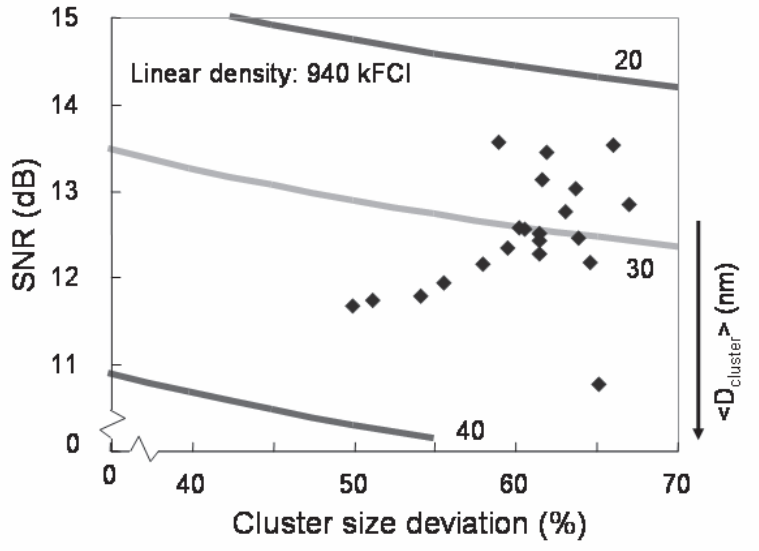

Fig. 7 SNR versus cluster size deviation. The contour lines of average cluster size are also plotted.

り, SN 比の向上には平均サイズの低減に注力した方が効果的であ るという開発指針が得られる. 


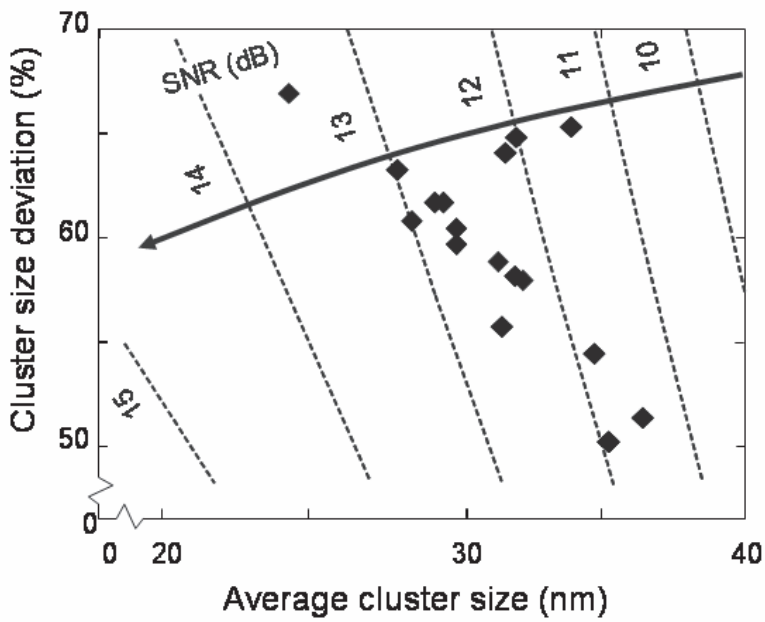

Fig. 8 Correlation between average cluster size and cluster size distribution. Dotted curves are the SNR contour lines.

以上の結果をまとめて平均サイズとサイズ分散の相関の グラフ上に SN 比の等高線をプロットしたものを Fig. 8 に 示す。平均サイズとサイズ分散はトレードオフの関係にあ るが，平均サイズが小さい媒体の方が $\mathrm{SN}$ 比が高い事が 1 つのグラフで確認できる. 最も効果的に SN 比を向上する には等高線に直交する方向に媒体開発を進めればよい。一 方，低クラスタサイズ領域では等高線の傾きが緩慢になる 傾向がありサイズ分散の影響が相対的に大きくなる事が示 唆される。従って，開発中の媒体に合わせた指針の明確化 が重要である.

\section{5. まとめ}

記録媒体の磁気クラスタサイズ分布と信号品質の関係を 実験とシミュレーションを併用して検討した。重回帰分析 により SN 比とクラスタサイズ分布の関係を調心，両者の 関係を定量化した。その結果，平均クラスタサイズとクラ
スタサイズ分散の低減はいずれも SN 比の向上に効果的で あるが，改善効果の大きい平均サイズの低減により注力す べきという開発指針が得られた。一方で，低クラスタサイ ズ領域ではサイズ分散の影響が相対的に増加する傾向も確 認された。従って，開発中の媒体に合わせた指針の明確化 が重要であり本研究で提案した評価解析手法は有効である.

謝辞 本研究を遂行するにあたり，日立製作所中央研究所 の柏瀬英一氏，浦上洋輔氏，椎本正人氏，片田裕之氏，西 田靖孝氏，棚橋究氏，根本広明氏にはご議論・ご助言を頂 きました。感謝いたします。

\section{References}

1) K. Miura, H. Muraoka, Y. Sugita, and Y. Nakamura: J. Magn. Soc. Jpn., 24, 231 (2000)

2) K. Miura, D. Sudo, M. Hashimoto, H. Muraoka, H. Aoi, and Y. Nakamura: IEEE Trans. Magn., 42, 2261 (2006).

3) M. Hashimoto, K. Miura, H. Muraoka, H. Aoi, R. Wood, M. Salo, and Y. Ikeda: J. Magn. Magn. Mater., 320, 2935 (2008)

4) M.Takahashi, A. Kikuchi, H. Hara, and H. Shoji: IEEE Trans. Magn., 34, 1573 (1998)

5) T. Shimatsu, T. Okiawa, Y. Inaba, H. Muraoka, and Y. Nakamura: IEEE Trans. Magn., 39, 2335 (2003).

6) S. Takenoiri, Y. Sakai, K. Enomoto, S. Watanabe, and H. Uwazumi: IEEE Trans. Magn., 39, 2279 (2003).

7) M. Kitano, E. Miyashita, N. Hayashi, and S. Takenoiri: IEEE Trans. Magn., 43, 2094 (2007)

8) H. Nemoto, I. Takekuma, H. Nakagawa, T. Ichihara, R. Araki, and Y. Hosoe: J. Magn. Magn. Mater., 320, 3144 (2008)

9) M. Hashimoto, H. Nakagawa, K. Nakamoto, and H. Ide: $J$. Magn. Soc. Jpn., 33, 216 (2009)

10) M. Hashimoto, H. Nakagawa, K. Nakamoto, H. Ide, and T. Ichihara: IEEE Trans. Magn., 45, 3718 (2009).

11) K. Nakamoto, H. Hoshiya, H. Katada, T. Okada, M. Hatatani, K. Hoshino, N. Yoshida, I. Nunokawa, K. Etoh, and K. Watanabe: IEEE Trans. Magn., 41, 2914 (2005).

12) Z. Lin, T. Lam, X. Che, and X. Sui: IEEE Trans. Magn., 41, 3067 (2005).

13) B. Valcu, T. McDaniel, and X. Wang: IEEE Trans. Magn., 45 , 3565 (2009).

2009年10月15日受理，2010年1月27日再受理，2010年3月17日採録 